\title{
Fernando Copello, Marina Letourneur y Lucie Valverde (comps.), 3 poetas 3. Ensayos sobre la infancia en la obra de Juan Gelman, Alejandra Pizarnik y María Elena Walsh. Buenos Aires, Dedalus, 2020
}

Virginia Bonatto

Cita sugerida: Bonatto, V. (2021). [Revisión del libro 3 poetas

3. Ensayos sobre la infancia en la obra de Juan Gelman,

Alejandra Pizarnik y María Elena Walsh por F. Copello, M.

Letourneur y L. Valverde (comps.)] . Orbis Tertius, 26(34),

e221. https://doi.org/10.24215/18517811e221

Acompañando un título que a su vez es un hallazgo poético - eco de una dedicatoria en la que María Elena Walsh escribía “ 4 besotes 4 " - y cuyos signos gráficos se descomponen con lúdica revuelta en la colorida tapa, el subtítulo de esta compilación a cargo de Fernando Copello, Marina Letourneur y Lucie Valverde, Ensayos sobre la infancia en la obra de Juan Gelman, Alejandra Pizarnik y María Elena Walsh, es una promesa de lectura original y definitivamente necesaria. Editado en Buenos Aires por Dedalus Editores, el volumen reúne un ensayo sobre Juan Gelman, dos sobre Alejandra Pizarnik, tres sobre María Elena Walsh y una conversación con Betty Sapollnik, amiga de infancia de Alejandra Pizarnik. Abren la lectura unas palabras preliminares de los compiladores (miembros del Laboratorio 3L.AM - Lengua, Literaturas, Lingüística de las Universidades de Le Mans y de Angers), mediante las cuales se establecen algunos ejes comunes a los tres poetas argentinos nacidos en la década del treinta y se subraya un tratamiento particular, en cada uno de ellos, del periodo de la infancia. Uno de los aciertos del libro tiene que ver con el cruce entre las dimensiones biográfica y estética que acompaña la rigurosa mirada teórica y filológica de cada capítulo reponiendo las trayectorias personales, subjetivas, ideológicas y políticas como claves indispensables de lectura de tres poéticas situadas. 
Como señalan Copello, Letourneur y Valverde en la apertura del volumen, "hablar del niño es para cada poeta una manera privilegiada de hablar de sí mismo siendo al mismo tiempo el otro, el que permaneció en el pasado" (p. 13). Infancia y muerte son, por ejemplo, ingredientes solidarios en Gelman y en Pizarnik. En el primero, el niño es víctima de un mundo injusto y su voz expresa una ética y un humanismo que socavan cualquier régimen de autoridad y violencia. En Pizarnik $-\mathrm{y}$ tal vez aquí reside una de las mayores apuestas del libro-, la infancia significa más que un espacio infernal, ya que, como se abordará en los dos capítulos que la estudian y como permiten ver los recuerdos que emergen durante la entrevista con Betty Sapollnik (vecina y compañera de escuela de "Buma"), tiene que ver también con la inocencia y la dimensión del juego que son constitutivas de la escena verbal. En relación con la obra de María Elena Walsh, la apuesta es doble: la inclusión de la autora de Tutú Marambá entre dos voces mucho más canonizadas por el ámbito académico restituye el aporte intelectual y artístico de su obra poética y ensayística a las letras argentinas e hispanoamericanas, e invita a pensar la relación con la infancia ya no desde la consideración del público más comúnmente asociado a su vasta producción sino desde la solidaridad epistemológica y productiva entre palabra poética y niñez, aspectos que echan luz, a su vez, sobre la obra poética de los otros escritores.

El capítulo dedicado a Juan Gelman, escrito por Geneviève Fabry ("Juan Gelman y la infancia como lenguaje"), lleva a cabo una pesquisa lingüística e intertextual que ilumina la percepción del dolor y de la pérdida en la extensa obra poética gelmaniana a partir de la consideración de la infancia como lenguaje. Situadas en el meollo de la ética y de la política, la mirada y la voz infantiles articulan resistencia y alteridad, en un nivel que, si bien traduce con esmerado extrañamiento aspectos biográficos, debe leerse, de acuerdo con la propuesta de la autora, como una concepción compleja acerca de la poesía y del lenguaje.

Los dos capítulos en torno a la obra de Alejandra Pizarnik restauran la dimensión infantil presente en su poética desde una óptica novedosa. Ivonne Bordelois ("Alejandra Pizarnik: la inocencia terrible") conoció muy de cerca a Pizarnik y en ese sentido cobran un interés especial las distintas respuestas ensayadas en relación con la pregunta que formula al comienzo de su contribución: “¿Puede una poeta maldita hablar de la inocencia o representarla?” (p. 34). Las expresiones sobre la idea de inocencia que la autora rastrea en entrevistas, poesías y textos en prosa de Pizarnik, así como en los recuerdos de su amistad con ella, le permiten sugerir que la inocencia no se traduce en el discurso pizarniano como ignorancia del mal, sino como incapacidad de daño. La inocencia activa, según Bordelois, supone una lucha contra un daño inicial y se mantiene como eje a lo largo de las tres edades que conviven en esta poética: la infancia como juego, asombro y ternura; la adolescencia como inquietud y angustia, y la adultez como sabiduría y lucidez. Edgardo Dobry, por su parte, realiza en el capítulo "À défaut d'autre chose: glosolalia y poética bucanera" un recorrido etimológico e histórico del vocablo infancia que culmina en la radicalización de distintas formas de puerilidad durante el modernismo y la primera vanguardia del siglo XX. Por vía de Lautréamont y de Artaud, el autor arriba a la poesía de Pizarnik y a su registro insistente sobre la dificultad de acceder a la lengua. De acuerdo con Dobry, la deliberada posición infantil en la escritora argentina agrega a la modernidad poética "la radicalidad de la escisión entre voz y palabra" (p. 58). La glosolalia, como pensamiento de la voz, se combina con el collage de citas literarias de una manera que complejiza radicalmente el balbuceo de DADA que le sirve a la autora de trampolín poético.

Los tres ensayos sobre María Elena Walsh constituyen valiosos acercamientos a tres preocupaciones de esta poeta: educación, feminismo y afinidad entre infancia y lengua poética. Por distintas vías, Fernando Copello, Gabriele Hassler y Maud Gaultier demuestran que el aporte intelectual, literario y cultural de Walsh excede los reconocimientos más habituales en los espacios del espectáculo infantil y de la escuela. En el capítulo "Vacas que estudian y contexto escolar en la poesía de María Elena Walsh", Fernando Copello se aproxima a la trayectoria escolar, en el barrio de Ramos Mejía, de la autora de "Manuelita la tortuga" y de tantos otros entrañables hitos de la literatura y la canción infantiles de nuestro país. Entendiendo que la escuela constituye un territorio esencial en su poética, Copello rastrea en la obra literaria y ensayística de Walsh las novedosas y revolucionarias representaciones de ese universo y de sus protagonistas. El análisis del famoso poema "La vaca 
estudiosa" (Tutú Marambá, 1960) revela con detalle otras capas que se superponen a la inversión carnavalesca del escenario escolar, como el folclore inglés (con la tradición del nonsense) y latinoamericano (donde aflora la sensibilidad de la autora por el ámbito rural), y los resabios de fábula y de sátira. En “'Madre de las odas': la maternidad en la poética (feminista) de María Elena Walsh”, Gabriele Hassler trabaja con el corpus menos estudiado de la producción para el público adulto. Con Hecho a mano (1965), Walsh inaugura una voz poética en la que interviene - además de lo infantil y lo popular - lo político, lo intelectual y lo feminista, y que se construye como una subjetividad no literaria y artesanal. Pero será fundamentalmente la metáfora de la maternidad, especialmente en la poética de fines de los años setenta, la que le permitirá a Walsh establecer una genealogía de mujeres creadoras a partir de la cual se interrogan modos alternativos y no masculinos de pensar la autoría y se entabla un diálogo con los discursos feministas de la época. En "Infancia y poesía en María Elena Walsh", Maud Gaultier se propone definir el quehacer literario de la autora de Ramos Mejía a partir de la exploración de las afinidades profundas entre el género poético y la niñez. De acuerdo con esta premisa, existe un vínculo metafórico entre poesía e infancia que se explica no ya desde la aproximación al público infantil como destinatario de las obras escritas sino desde las dimensiones epistemológica y cognitiva de un lenguaje que concibe la palabra como objeto material (y la valora en su sonoridad, musicalidad y comicidad) y que se presenta en tensión con el eje de la corrección lingüística. Las preferencias de María Elena Walsh por las nursery rhymes inglesas y por el folclore europeo y latinoamericano perciben en la infancia, antes que un público para agradar y educar, una compañera en la aventura poética.

El volumen se cierra con una entrevista a Betty Sapollnik, realizada en el año 2014 por Elena Savransky y Fernando Copello. La amiga de infancia de la poeta de Avellaneda rememora los tiempos de la educación inicial y primaria de ambas en la escuela judía, donde a Flora Alejandra Pizarnik, o "Buma" para su familia y amigos, la apodaban "Blúmele". En el cálido intercambio entre entrevistadores y entrevistada aparecen canciones (aquella tristísima en idish que Pizarnik anota en la entrada del martes 20 de diciembre de 1960 de sus Diarios), espacios (la calesita frente a la casa de "Buma" y los salones de la escuela por donde las dos únicas niñas del grupo corrían fuera de la vista de los adultos), personas (como los maestros refugiados, procedentes del Instituto Pestalozzi de Europa) y sensaciones (la observancia estricta de las familias judías en relación con las amistades en el barrio y el distanciamiento de las amigas a medida que van creciendo y Alejandra se convierte en una adolescente "extravagante").

El tenor íntimo y anecdótico del capítulo final cobra un valor adicional en el marco de este volumen dedicado a tres escritores de la vanguardia poética argentina de la segunda mitad del siglo XX. Con el cuidado académico que ello exige y que la compilación logra con creces, los seis ensayos y la conversación dejan ver que la reclamada conexión del arte con la vida pide también ser leída — más allá de la reconstrucción de los términos sociales y culturales con los cuales las innovaciones poéticas entraron en diálogo-a partir de la reposición de aquello que de singular y situado tiene cada trayectoria biográfica, y desde donde la vida se transustancia en gesto poético. 